\title{
On an instrument resembling the sextant, by which angles with the horizon can be measured
}

\section{E.H. Amagat}

To cite this article: E.H. Amagat (1885) On an instrument resembling the sextant, by which angles with the horizon can be measured, Philosophical Magazine Series 5, 19:121, 515-516, DOI: $10.1080 / 14786448508627711$

To link to this article: http://dx.doi.org/10.1080/14786448508627711

册 Published online: 29 Apr 2009.

Submit your article to this journal $[\pi$

Џ Article views: 2

Q View related articles 두 
until ten or twelve minutes after making the circuit; from this maximum point the strength of the current gradually diminishes. Fig. 2 shows the action of the same battery with ten ohms external resistance. Under these conditions we find at the instant of making circuit a strong current, which rapidly diminishes within the first five minutes to one sixth of its first strength.

Knowing the distance of the galvanometer from the sensitive paper, the strength of the current may be calculated by measuring the distance between the two lines at any instant, and proceeding as with an ordinary galvanometer and scale.

From a comparison of the two figures the electromotive force may be determined by $\mathrm{Ohm}$ 's law, if the distance between the lines is measured at the instant the current is made. Then knowing the electromotive force, current, and external resistance, we can readily find the internal resistance. .This resistance will be the liquid resistance of the cell only for the moment that the circuit is made, for afterwards the variation in electromotive force due to polarization, and the change in resistance of the liquid due to electrolytic action will combine to cause changes. Since, howevel, the changes in electromotive force due to polarization are much more rapid in their action than the changes in battery resistance, a very small error will be introduced if we compare points near each other on those parts of the curve in which the variation in current is greatest: during the small fraction of a minute that is taken, the change in battery-resistance will be infinitesimal and may be neglected.

We have selected these photographs as an example of the large variations that some batteries present, and the consequent usefulness of some such way of studying their action. From measurements upon these photographic charts the variations in electromotive force and internal resistance can be studied by obtaining such charts under different conditions of external resistance. It is evident that the same photographic method can be emplored to study the swing of the needle of a short coil-galvanometer, which indicates the gradual heating of a thermopile: In this way the conduction of heat along a bar could be studied.Silliman's American Joumal, May 1885.

Jefferson Physical Laboratory.

ON AN INSTRUMENT RESEMBLING THE SEXTANT, BY WHICH ANGLES WITH THE HORIZON CAN BE MEASURED. BY E. H. AMAGAT.

Imagine a sextant of which the optical axis of the telescope, instead of being oblique in reference to the fixed mirror, which $\mathrm{I}$ shall call B, is perpendicular to it. Arrange the movable mirror $\mathbf{A}$ so that its axis of rotation coincides with one of its edges, and cuts the optical axis. Suppose that the mirror B, instead of being fixed, is movable about an axis parallel to the plane of the graduated circle, and perpendicular to the optical axis; in these conditions, 
the image twice reflected from any given point will be displaced in a plane perpendicular to that of the circle, when $B$ turns about its axis. If the circle is placed horizontally, all the objects on the same vertical plane will be seen to pass in succession.

Now let us suppress the telescope, and replace it by a simple vertical slit placed between the eye and the axis of rotation of $A$; suppose, moreover, the mirror is silvered all over. By placing the eye at a convenient height in front of the slit, we can look directly at an object above or below the mirror (according to its height), and we can make it coincide with the image twice reflected of another object which may be at any height, since the movement of $B$ may bring it vertically to the desired height. A reading made as with the sextant will give at once the angle of the two objects projected on the horizon, such as would be obtained with a graphometer.

It follows from the preceding that the coincidence should be exact with the image of the axis of rotation or vertical edge of $A$, which would reduce to zero the field of the objects seen in $B$ by double reflection; but it is easy to see that by slightly inclining the visual ray so as to have a sufficient field, the error produced will be extremely small from the properties of minima, since we move but little from the position in which the error is completely nullified; with a small instrument which is only 7 centimetres in the side, an operator who is but little practised may take, in a few seconds, angles with sufficient accuracy for most ordinary operations; the approximation mainly depends on the horizontality of the instruments. Although the coincidence becomes more difficult and the exactitude less for very large angles, we may work directly up to $140^{\circ}$.-Comptes Rendus, A pril 27, 1885.

ON THE PRODUCIION OF ALTERNATING CURRENTS BY MEANS OF

A DIRECT-CURRENT DYNAMO-ELECTRIC MACHINE. BY JOHN TROWBRIDGE AND HAMMOND VINTON HAYES.

It is often desirable to transform a direct current into an alternating one for the purpose of obtaining electricity of high tension by means of a Ruhmkorff coil, for studying the effects of stratifications in vacuum tubes, or for employing alternating currents in the study of magnetism. The best way is undoubtedly to employ an alternating dynamo-electric machine, as has been done by Spottiswoode. When, however, only a direct-current machine is available, the following method can be employed:-

The dynamo machine, if it is not a shunt-wound machine, is shunted by a suitable resistance. We hare employed for this purpose thin ribbon-steel about 1.5 centim. broad and 01 millim. in thickness. The remaining portion of the current from the machine is conducted to two brass or copper segments $a$, $a^{\prime}$, fig. 2. This current is led to the primary coil, for instance, of a Ruhmkorff coil from two other segments $b, b^{\prime}$. These segments are fixed upon a 